\title{
WEAKENING THE BOND STRENGTH OF LUTING AGENTS COULD BE A GOAL IN IMPLANT RETAINED PROSTHETICS
}

\author{
Mostafa A Abdellatif* and Mohammed Moustafa Shalaby **
}

\begin{abstract}
Aim of the study: The current study was conducted to provide a simple practical technique to relatively weaken the bond strength of E.max Press copings retained to zirconia implant abutment models. This technique should facilitate crown retrieval from onto implant abutments without affecting the integrity of the ceramic crowns, abutment or the implant's integration, yet, the crown is still well retained during service.
\end{abstract}

Materials and methods: Twenty four zirconia implant abutment models were specially fabricated for the current study, to which 24 e.max press copings were cemented. According to the cementation technique, the samples were divided into four groups, 6 samples each. In Gp A, copings were cemented with a temporary resin luting cement without any surface treatment to the abutment models or the intaglio surfaces of the copings. In Gp B, abutments' surfaces as well as intaglio surfaces of the copings were treated according to manufacturers' instructions before cementation with permanent resin luting cement. In Gp C, abutments' surfaces were coated with a single coat of fresh whole saliva before cementing copings with the permanent resin luting cement. In Gp D, same as in Gp C with replacement of saliva with single coat of glycerin. All assemblies were then subjected to aging through thermocycling for 5000 cycles.

All assemblies were then tested for retention of coping cemented to the zirconia implant abutment models and failure surfaces were then examined by stereomicroscope to detect the mode of failure.

Results: All samples in Gp A failed before any mechanical testing. Gp C reviled insignificant bond strength results compared to Gps B and D. However, Gp D showed significant reduction in bond strength compared to Gp B.

Conclusions: Glycerin coating of zirconia implant abutments before use of permanent resin luting cement would be a good technique to retain crown in place for longer time, yet still liable to easy retrieval.

KEY WORDS: Zirconia abutments, Crown retrieval, Glycerin, Bond wakening

* Associate Professor of Dental Materials Science, Biomaterials Department, Faculty of Oral and Dental Medicine, Future University in Egypt, FUE.

** Lecturer of Fixed Prosthodontics, Fixed Prosthodontics Department, Faculty of Dentistry, Minia University, Egypt. 


\section{INTRODUCTION}

Implant dentistry is continually progressing. Now, dentists are placing implants as a standard mean for replacing missing teeth as they allow the preservation of the integrity of sound teeth adjacent to the edentulous space used to be abutments for fixed prosthesis. Although titanium abutments have been utilized for many years owing to their superior properties such as biocompatibility and corrosion resistance ${ }^{1}$, one of their weaknesses is the greyish appearance of the implant restorations through thin soft tissues biotypes ${ }^{2}$. The high esthetic demand leads to the introduction of metal free restorations that provides better esthetics in the esthetic areas ${ }^{3}$. The promising features of the metal free restorations gave the implant manufacturers the chance to replace titanium abutments with metal free ones. Zirconia implant abutments compared to other tested ceramic abutments have proven to be a good substitute to titanium ones with more esthetically pleasing appearance. The tooth-like color, tissue tolerance and high mechanical properties of yttria-stabilized tetragonal zirconia polycrystalline (Y-TZP) as well their longevity and their comparable fatigue strength under cyclic loading in water with metal ceramic restorations. This made it the ceramic material of choice when manufacturing esthetic implant abutments ${ }^{4}$. The retention of the implant prosthesis to the abutment was thoroughly discussed, but till now there is no single technique that combines good retention, good esthetics and good retrievability when needed. There are two types of implants restorations according to the used abutments; either screw - retained or cement - retained restorations. Abutments used for screw-retained implant restorations were industrialized in response to the need of retrievability. However, screw retained ones may suffer from esthetic problems and compromised occlusion ${ }^{5}$. Also, they are not the first choice by operators as their use is more technique sensitive as well as more expensive in contrast to cement retained implant ones ${ }^{6}$. Furthermore, they do not provide passive adaptation of the implant prosthetic restoration ${ }^{7}$.

The retention is an important factor in the success of the implant retained prosthesis ${ }^{8}$. The retention and the resistance of the cement-retained prosthesis is affected by the abutment features, luting cement, and the restoration features ${ }^{9}$. The features of the abutment include their width, height, degree of taper, and surface roughness ${ }^{10,11}$. Yet, their material is another factor for the restoration retention. The type of the luting cement, its composition, film thickness, and seating pressure and duration while cementation also affect the final retention. The material of the final restoration, fitness, and the intaglio surface roughness are another controlling factors ${ }^{12}$. The ideal luting cement should provide adequate retention while not affecting the accessibility to the superstructure and the abutment whenever needed 13. Permanent cements allow for a superior retention, acceptable marginal seal but endanger the retrievability of the components ${ }^{14}$. The obtained strong bond leads to the use of aggressive techniques for these prosthesis retrieval. That in many cases would result in fracture of crown, abutment screw, abutment, and/or implant ${ }^{15}$. The use of temporary cements has been practiced for long periods in dental offices to allow for safe retrieval of crowns when needed. However, they might result in insufficient strength during function, leaching out of the cement, and consequently prosthesis fracture ${ }^{16}$. For better simulation of clinical conditions, investigation of the bonding or retentive strength should be studied using axial dislodgment forces.

Large number of articles discussed the use of resin cement for bonding lithium disilicate crowns to either titanium or zirconia abutments. All these articles focused on the material and technique for improving bond strength. However, they ignored the difficulty of retreivability with such strong bond. 
The current study was conducted to provide a simple practical technique to relatively weaken the bond strength of E.max Press copings retained to zirconia implant abutment models. This technique should facilitate crown retrieval from onto implant abutments without affecting the integrity of the ceramic crowns, abutment or the implant's integration, yet, the crown is still well retained during service. The null hypothesis was that there was no difference between different protocols to decrease the retention bond strength of ceramic crowns retained to zirconia implant abutments after they have been aged with thermocycling.

\section{MATERIALS AND METHODS}

\section{Materials}

The materials used in the current study are listed in Table 1.

TABLE (1) List of materials used in the current study with their composition.

\begin{tabular}{|c|c|c|c|c|}
\hline Manufacturer & Material & & Batch No. & Composition \\
\hline $\begin{array}{c}\text { Ivoclar Vivadent } \\
\text { AG, Schaan } \\
\text { Liechtenstein }\end{array}$ & IPS e.max press & Shade MT A2 & Y19856 & $\begin{array}{l}\mathrm{SiO}_{2} 57-80 \mathrm{wt} \% \\
\mathrm{Li}_{2} \mathrm{O} 11-19 \mathrm{wt} \% \\
\mathrm{~K}_{2} \mathrm{O} 0-13 \mathrm{wt} \% \\
\mathrm{P}_{2} \mathrm{O}_{5} 0-11 \mathrm{wt} \% \\
\mathrm{ZrO}_{2} 0-8 \mathrm{wt} \% \\
\mathrm{ZnO} 0-8 \mathrm{wt} \% \\
\text { Other oxides and ceramic pigments } 0 \text {-wt } 10 \%\end{array}$ \\
\hline $\begin{array}{c}\text { Zirkonzahn SRL, } \\
\text { Italy }\end{array}$ & $\begin{array}{l}\text { ZIRCONIA } \\
\text { Prettau® }\end{array}$ & Translucent & ZB4252C & $\begin{array}{l}\mathrm{ZrO}_{2} \text { Main component } \\
\mathrm{Y}_{2} \mathrm{O}_{3} 4-6 \% \\
\mathrm{Al}_{2} \mathrm{O}_{3}<1 \% \\
\mathrm{SiO}_{2}<0.02 \% \\
\mathrm{Fe}_{2} \mathrm{O}_{3}<0.01 \% \\
\mathrm{Na}_{2} \mathrm{O}<0.04 \%\end{array}$ \\
\hline $\begin{array}{c}\text { Ivoclar Vivadent } \\
\text { AG, Schaan } \\
\text { Liechtenstein }\end{array}$ & $\begin{array}{c}\text { Variolink@ } \mathrm{N} \\
\text { Dual-curing luting } \\
\text { composits }\end{array}$ & $\begin{array}{l}\text { Transparent, } \\
\text { low viscosity }\end{array}$ & U16084 & $\begin{array}{l}\text { Barium glass filler, mixed oxide ( } 48.4 \mathrm{wt} \% \text { in base } \\
\text { paste and } 46.2 \mathrm{wt} \% \text { in catalyst paste) } \\
\text { Dimethacrylates( } 26.3 \mathrm{wt} \% \text { in base paste and } 27.9 \mathrm{wt} \% \\
\text { in catalyst paste) } \\
\text { Ytterbiumtrifluoride ( } 25 \mathrm{wt} \% \text { in base paste and } 25 \mathrm{wt} \% \\
\text { in catalyst paste) } \\
\text { Initiators and stabilizers ( } 0.3 \mathrm{wt} \% \text { in base paste and } 0.9 \\
\text { wt } \% \text { in catalyst paste) } \\
\text { Pigments }(<0.1 \mathrm{wt} \% \text { in base paste and }<0.1 \mathrm{wt} \% \text { in } \\
\text { catalyst paste) }\end{array}$ \\
\hline $\begin{array}{l}\text { Kerr Corporation, } \\
\text { West } \\
\text { Orange, U.S.A. }\end{array}$ & TempBond. Clear & Translucent & 5512765 & $\begin{array}{l}\text { Base paste: } \\
\text { - } 2 \text {-hydroxyethyl methacrylate }<50 \% \\
\text { - } 2 \text {-pyridylthiourea }<50 \% \\
\text { - } 3 \text {-Methacryloxypropyltrimethoxysilane }<50 \% \\
\text { Catalyst paste: } \\
\text { - } \quad \text { Dibutyl Phthalate } 10-15 \% \\
\text { - } 3 \text {-Methacryloxypropyltrimethoxysilane }<50 \% \\
\text { - } \quad \text { Dibutyl Phthalate } 10-15 \% \\
-\quad \alpha, \alpha \text {-dimethylbenzyl hydroperoxide; cumene } \\
\quad \text { hydroperoxide }<10 \% \\
\text { - } \quad \text { silica, amorphous, crystalline-free substance }<1 \%\end{array}$ \\
\hline
\end{tabular}




\begin{tabular}{|l|l|l|l|l|}
\hline \multicolumn{1}{|c|}{ Manufacturer } & \multicolumn{1}{|c|}{ Material } & & Batch No. & \multicolumn{1}{c|}{ Composition } \\
\hline $\begin{array}{l}\text { ITENA, Paris, } \\
\text { FRANCE }\end{array}$ & $\begin{array}{l}\text { DE N T O B O N D } \\
\text { Porcelain etch and } \\
\text { Porcelain Silane }\end{array}$ & $\begin{array}{l}4167-29 \\
\text { PFXE }\end{array}$ & \\
\hline $\begin{array}{l}\text { Vertex-Dental BV, } \\
\text { Netherlands }\end{array}$ & $\begin{array}{l}\text { Next Dent Cast } \\
\text { 3D printing } \\
\text { material for } \\
\text { Castable parts }\end{array}$ & Purple & XH244N03 & \\
\hline $\begin{array}{l}\text { Herr Konig, } \\
\text { A.A.K., Egypt }\end{array}$ & Glycerin Pure & Transparent & & Pure glycerin 100\% \\
\hline
\end{tabular}

\section{Methods}

\section{Zirconia abutment model preparation:}

In this study, 24 zirconia models were constructed to resemble a prepared zirconia implant abutment. These zirconia models were designed using SolidWorks software running on a ACER computer with Intel ${ }^{\circledR}$ Core TM i5 -430M processor $(2.26 \mathrm{GHz}$, 3MB L3 cache), (SolidWorks ${ }^{\circledR}$ Premium 2013 x64 Edition). The models were in the dimensions of $7 \mathrm{~mm}$ in height and $5 \mathrm{~mm}$ in diameter at the base with 6 degree tapering and $1 \mathrm{~mm}$ shoulder finish line. Each model had a base to facilitate its fixation in the mechanical testing machine during the retention test. The model features were then sent in the form of STL file to the Computer Aided Designing (CAD) software Exocad 2019 (Exocad Dental, Darmstadt, Germany). Through CAD software, the STL file was sent to the associated Computer Aided Milling (CAM) machine controlled with MillBox DGSHAPE Edition v3.7.3 software to soft mill zirconia abutments from partially sintered blocks ZIRCONIA Prettau ${ }^{\circledR}(Z B 4252 C$, Zirkonzahn SRL, Italy). The models were then fully sintered in a sintering furnace (Mihm-Vogt, Tabeo, GmbH \& Co. $\mathrm{KG}$, Germany) at $1600^{\circ} \mathrm{C}$ for 8 hours according to the manufacturer's instructions.

\section{IPS e.max press coping preparation:}

For each abutment model, a digital coping model was designed by SoildWorks software and sent to CAD software as STL file too. The intaglio surface of the digital coping model was planned to exactly fit the milled abutment models with $30 \mu \mathrm{m}$ internal relief, while externally it was designed in the form of cylinders with occlusal thickness $3.5 \mathrm{~mm}$. A $1 \mathrm{~mm}$ in diameter through and through hole was added 2 $\mathrm{mm}$ away from the occlusal table of in this occlusal thickness to later facilitate retention testing. This STL file was then sent to DentCase 3D printer (Mogassam, Egypt) that is controlled by Autodesk netfabb premium 2018 software to construct resin coping models made from 3D printing resin for castable parts (Next Dent ${ }^{\circledR}$ Cast, XH244N03, Vertex-Dental BV, Netherlands). The resin copings were then invested with phosphate-bonded investment material for the press technology (IPS Press Vest Premium, Ivoclar Vivadent AG, Schaan Liechtenstein). Then, the invested resin copings models were placed upside down inside a burnout furnace to be gradually preheated for one hour then immediately were transferred to the pressing furnace (Programat EP 3000, Ivoclar Vivadent AG, Schaan, Liechtenstein). The IPS e.max press ingot (Y19856, Ivoclar Vivadent AG, Schaan, Liechtenstein) was plasticized at $920^{\circ} \mathrm{C}$ before isostatically pressed under vacuum into molds. After gradual controlled 
cooling and devesting, the sprues were cut and their connection sites were smoothed using rotary grinding and polishing kit (EVE, VDDI, Dental Solutions, Germany).

\section{Grouping and cementation techniques:}

The abutment models were then randomly divided into 4 groups according to the method by which the corresponding ceramic copings would be cemented to; $n=6$. The copings in the first group (Positive control, Gp. A), were cemented using translucent commercially available temporary cement for ceramics (TempBond. Clear, 5512765, Kerr Corporation, West Collins Orange, U.S.A.). Neither of the intaglio surfaces of the copings, nor surfaces of the abutment models did receive any surface treatment.

In the second group (Negative control, Gp. B), zirconia abutments were coated with a single coat of Z-PRIME (BISCO Inc., Schaumburg, U.S.A.) and air dried for 5 seconds. According to the manufacturer's instructions, the intaglio surfaces of the copings were acid etched with $8 \% \mathrm{HF}$ acid (DENTOBOND Porcelain etch, 4167-29 PFXE, ITENA, Paris, FRANCE) for 60 seconds, thorough water flushing followed by air drying till the etched surface appeared frosted white. A single coat of silane (DENTOBOND Porcelain Silane, 4167-29 PFXE, ITENA, Paris, FRANCE) was then applied to the etched ceramic surface and dried well with air spray. Then silinated copings were cemented to primed abutment models using transparent dual-curing - light-curing luting resin cement (Variolink ${ }^{\circledR}$ N, U16084, Ivoclar Vivadent AG, Schaan Liechtenstein).

In the third group (Intervention I, Gp. C), the abutment models were coated with a single coat of whole fresh saliva that was collected form the same individual and this is considered to be an acceptable method for saliva contamination testing ${ }^{17}$. Saliva was applied using a micro brush and air dried for
5 seconds prior to cementation with the same resin cement used in Gp. B without any previous surface treatment.

In the fourth group (Intervention II, Gp. D), the copings were cemented to the abutment models like in $\mathrm{Gp} . \mathrm{C}$ with replacing of the fresh saliva with a single coat of glycerin.

Either of temporary or resin cements used were applied to the intaglio surfaces of the copings using the brushing technique in order to be sure that there will be no excess cement that might prevent complete seating of the copings onto the zirconia models. The seating of these assemblies was done with manual pressure and then was completed by holding them under static load of $5 \mathrm{~kg}$ for 3 minutes using a universal testing machine (Model 3345; Instron Instruments Ltd, USA) and light cured from 3 different angles $120^{\circ}$ apart for 30 seconds each. Assemblies in each group were then aged by thermocycling for 5000 cycles at temperatures $5^{\circ} \mathrm{C}$ and $55^{\circ} \mathrm{C}$ with a dwelling time of 30 seconds in each bath and transferring time of 4 seconds which represents 6 months of intraoral service in the patient's mouth ${ }^{18}$.

\section{Retention test:}

The assemblies were then tested for retention of the cemented copings to the zirconia models by hanging the models using a $0.9 \mathrm{~mm}$ wire via the occlusal hole to the movable part of the universal testing machine. The samples were fixed to the testing machine via the base of the zirconia models. Retention was tested under tensile load till the detachment of the ceramic copings from the zirconia models. Axial force was applied at a cross-head speed of $1.0 \mathrm{~mm} / \mathrm{minute}$. The maximum load values at debonding were recorded using Analysis Of Variance (ANOVA) test at 5\% level of significance. For results with significant differences, Tukey's post hoc test was performed to determine the differences among the groups. Statistical analysis was done using statistical software SPSS 13.0 for Windows. 
The abutment surface was examined under a stereo microscope to verify the mode of failure after debonding whether adhesive, cohesive, or a combination. The failure surfaces of abutments were examined under a stereo microscope (LEICA MZ6) to which, a digital camera (LEICA MC 190 HD) was attached. The failed abutments' surfaces were examined at $16 \mathrm{X}$ to verify the mode of failure at the debonding area which may be either adhesive, cohesive, or a mixed.

\section{Statistical analysis:}

Data were collected, tabulated and statistically analyzed using the Statistical Package for Social Science (IBM SPSS) version 20 and were presented as means, and standard deviations. The comparison between the four techniques regarding quantitative data was done by using one way analysis of variance (ANOVA) test. The results were considered statistically significant at p-value less than or equal to 0.05 ( $\mathrm{p} \leq 0.05)$. For statistically significant results, Tukey HSD Post Hoc test was conducted to detect the differences among the groups.

\section{RESULTS}

The results of the current study reviled rejection of the null hypothesis. All samples of positive control failed during mounting on the mechanical testing machine before any testing, so all samples were considered as 0 value with statistical significant difference compared to the other three groups. On the other hand, the values of the negative control group should significant difference then intervention
II, but didn't differ significantly than intervention I. There was no significant statistical diffidence between interventions I and II, Table 2 and Figure 1. The mean retentive force value of the Gp. D was high enough to resist dislodgment of the crowns, yet still low that the crowns retained by this intervention can be removed in office when needed without adversely affecting neither the integrity of ceramic crowns, the implant retainedzirconia abutments nor the osseointegration around the dental implants.

Results of stereo microscope reviled that abutments models in Gp A showed adhesive failure between the luting cement and zirconia surface. Zirconia abutment models surfaces showed mixed adhesive and cohesive failures. A considerable amount of cement residues remained adherent to the abutment models' surfaces. Abutment models in Gps C and D showed much lower residues of the luting cement, Figure 2.

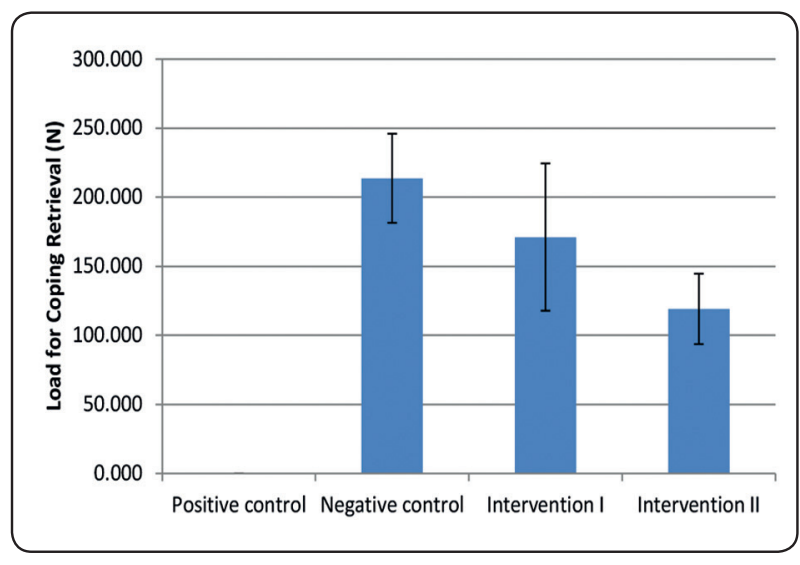

Fig. (1) Bar chart of mean (\& SD) load valued in $\mathrm{N}$ for the four tested groups.

TABLE (2) Mean and standard deviation (SD) of the retentive force values among the tested groups.

\begin{tabular}{|c|c|c|c|c|c|c|c|}
\hline \multicolumn{2}{|c|}{$\begin{array}{c}\text { Temporary } \\
\text { (Positive control, Gp. A) }\end{array}$} & \multicolumn{2}{|c|}{$\begin{array}{c}\text { Conv ttt } \\
\text { (Negative control, Gp. B) }\end{array}$} & \multicolumn{2}{|c|}{$\begin{array}{l}\text { Whole Saliva } \\
\text { (Gp C) }\end{array}$} & \multicolumn{2}{|c|}{$\begin{array}{l}\text { Glesryne } \\
\text { (Gp. D) }\end{array}$} \\
\hline Mean & SD & Mean & SD & Mean & SD & Mean & SD \\
\hline $0.000^{\mathrm{a}}$ & 0.000 & $213.732^{b}$ & 32.257 & $171.160^{\mathrm{bc}}$ & 53.299 & $119.155^{\mathrm{c}}$ & 25.485 \\
\hline
\end{tabular}




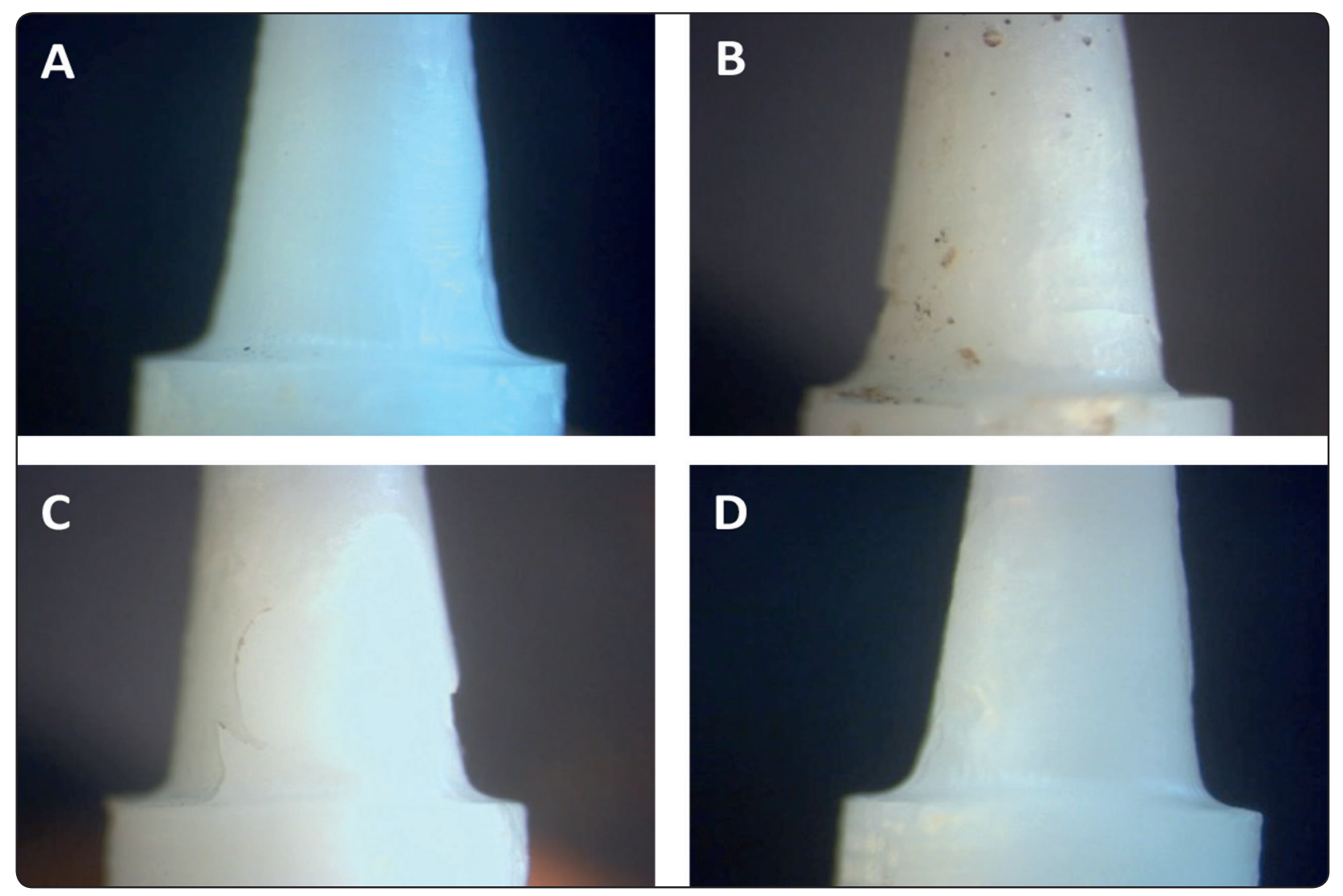

Fig. (2) Stereo microscopic images representing sample of the 4 tested groups showing the mode of failure and the residues of cements remaining onto the abutment models' surfaces at 16X. The letters are corresponding to each tested group.

\section{DISCUSSION}

Zirconia implant abutments are good option especially where the gum line location would affect esthetics of dental implants. Furthermore, the use of zirconia abutments eliminate the problem of dark color of metallic abutments which would enhance shade matching with the adjacent natural teeth ${ }^{19}$. Also, Zirconia has been reported as a high fracture resistant implant abutment material compared to other dental ceramics ${ }^{20}$.

Owing to their higher strength, lower solubility, better esthetics and longer term color stability compared to other translucent dental cements like glass ionomer, the use of resin cement becomes a routing for cementation of ceramic restorations especially in the esthetic zone ${ }^{21}$.
Hydrothermal aging by thermocycling for 5000 cycles is considered a common way to evaluate the resin bond to ceramics especially that the increase of cycles number to 10.000 or even 20.000 did not have significant effect on results ${ }^{22,23}$.

All copings cemented with TempBond Clear temporary cement showed failure during mounting assemblies on the testing machine before any mechanical testing, revealing the negative effect of thermocycling on the temporary cement. Zirconia abutment models showed adhesive failure at cement/zirconia interface resulting in clean abutment surfaces. This clean abutment surface could be an advantage not to disturb implant abutment complex during removal of cement residues. The existence of $10-15 \%$ dibutyl phthalate in the TempBond catalyst paste which is an efficient plasticizer may 
contribute to its weakening especially after thermocycling ${ }^{24}$. No plasticizers were claimed to exist in the other used cement.

In contrast to this study, a study conducted to evaluate the effect of thermocycling on the bond strength of different temporary cement showed that TempBond Clear needed an average force of 23.3 $\mathrm{N}$ to retrieve copings. However, this contrast could be attributed the only 190 thermocycles applied in this study compared to 5000 cycles in the current study, as well as the nature of the adherends used in this study where cements were used to bond acrylic resin copings to prepared natural human molars ${ }^{25}$.

On the other hand, the values of the negative control group would interfere with easy and safe retrieval of ceramic crowns from onto implant abutments without high risk of chipping or even fracture of ceramic crowns and/or zirconia abutments as well as affecting osseointegration around the implants. Furthermore, the remaining cement onto zirconia abutment models needs extra steps to remove the residues risking the abutment, implant and/or integration with bone.

The effect of salivary contamination on the bond strength of different resin cements has been investigated in many studies, however all these studies focused of this effect to dentin bonding. Many explanations have been proposed to the reduction in bond strength of different resin cements contaminated with saliva and water. Whole saliva contains up to $99 \%$ water hence saliva is considered a highly diluted solution. This high water content is believed to weaken bond strength of dental adhesives ${ }^{26}$. Glycoproteins in saliva and other high molecular weight macromolecules could be another cause to prevent proper adhesion of dental cements ${ }^{27}$. Furthermore, in a study conducted to investigate the bond strength of resin luting cements after salivary contamination, it was found that salivary contamination deteriorated the bond strength of investigated luting agents. This was attributed to presence of Bis-GMA in dental resin cements which may degrade by enzymes normally exist in human saliva breaking down the bonded interface ${ }^{28}$.

The results of saliva contaminated group; Gp C, may differ a little than previous study where reduction in bond strength was not significant than that in Gp. B. This difference might be due testing of bonded zirconia implant abutment rather than dentin surface. The residues of cement on zirconia abutment models revealed mixed mode of failure with little residues of cement remained onto abatement models.

The Gp D showed significantly lower bond strength values than Gp A but did not differ significantly than Gp B, and so the null hypothesis is partially rejected. Glycerin is a water soluble liquid ${ }^{29}$ that has been used in many researches as a lubricating material. Vieyra et al, $2015^{30}$, used glycerin as a lubricating material during making impressions for the root canals with self-curing acrylic resin for custom made posts, and they found it can be effectively removed from the root canals without any residues when rinsed with only $2 \mathrm{cc}$ of alcohol.

The idea of using glycerin as an isolating separating medium was also applied in 2016 by Ribeiro da Silva et al ${ }^{31}$ who used glycerin to isolate prepared exposed dentin before application of provisional restorations. Being viscous fluid yet water soluble, it was found that glycerin is an effective medium to facilitate easily removal of provisional restorations maintaining the integrity of underlying dentin surface.

Furthermore, the water solubility of the glycerin encouraged temporary cements' manufacturers to use it in their try - in esthetic resin cements pastes to help with temporary veneers cementation during verifying the selected shade ${ }^{32}$.

Owing to its oil like viscosity and water solubility, glycerin could be a good separating medium before ordinary resin cementation of ceramic crowns cemented to ceramic implant retained abutments in dental office. Furthermore, glycerin is transparent and clear hence does not affect the color of the used cement. The mixed mode of failure with the least 
remaining cement residues onto zirconia models would suggest that this technique is safe and easy one if retrieval of implant retained crown is needed.

\section{CONCLUSIONS}

Under limitation of the current study it can be concluded that:

1. The used temporary luting cement might fail soon resulting in early dislodgment of implant retained crown.

2. The use of resin luting cement for permanent use after full surfaces treatment of abutment or fitting surface of crown may hinder easy and safe retrieval of the implant retained crown when needed.

3. Glycerin coating of zirconia implant abutments before use of permanent resin luting cement would be a good technique to retain crown in place for longer time, yet still liable to easy retrieval.

\section{REFERENCES}

1. Kim J-T, Cho S-A. The effects of laser etching on shear bond strength at the titanium ceramic interface. The Journal of Prosthetic Dentistry. 2009 Feb;101(2):101-6.

2. Heydecke G, Sierraalta M, Razzoog ME. Evolution and use of aluminum oxide single-tooth implant abutments: a short review and presentation of two cases. Int J Prosthodont. 2002 Oct;15(5):488-93.

3. Gomes A-L, Montero J. Zirconia implant abutments: a review. Med Oral Patol Oral Cir Bucal. 2011 Jan 1; 16(1):e50-55.

4. Palacios RP, Johnson GH, Phillips KM, Raigrodski AJ. Retention of zirconium oxide ceramic crowns with three types of cement. J Prosthet Dent. 2006 Aug;96(2):104-14.

5. Armellini D, Bilko S, Carmichael RP, von Fraunhofer JA. Screw-Retained Prosthesis for Straumann Implant Sites with Limited Interocclusal Clearance. J Prosthodontics. 2006 May;15(3):198-201.

6. Squier RS, Agar JR, Duncan JP, Taylor TD. Retentiveness of dental cements used with metallic implant components. Int J Oral Maxillofac Implants. 2001 Dec;16(6):793-8.
7. Sheets JL, Wilcox C, Wilwerding T. Cement selection for cement-retained crown technique with dental implants. J Prosthodont. 2008 Feb;17(2):92-6.

8. Güncü MB, Cakan U, Canay S. Comparison of 3 luting agents on retention of implant-supported crowns on 2 different abutments. Implant Dent. 2011 Oct;20(5):349-53.

9. Akça K, Iplikçioğlu H, Cehreli MC. Comparison of uniaxial resistance forces of cements used with implantsupported crowns. Int J Oral Maxillofac Implants. 2002 Aug;17(4):536-42.

10. Bresciano M, Schierano G, Manzella C, Screti A, Bignardi C, Preti G. Retention of luting agents on implant abutments of different height and taper. Clin Oral Implants Res. 2005 Oct;16(5):594-8.

11. Akin H, Guney U. Effect of various surface treatments on the retention properties of titanium to implant restorative cement. Lasers Med Sci. 2012 Nov;27(6):1183-7.

12. Qeblawi DM, Muñoz CA, Brewer JD, Monaco EA. The effect of zirconia surface treatment on flexural strength and shear bond strength to a resin cement. J Prosthet Dent. 2010 Apr;103(4):210-20.

13. Pan Y-H, Lin T-M, Liu P-R, Ramp LC. Effect of Luting Agents on Retention of Dental Implant-Supported Prostheses. J Oral Implantol. 2015 Oct;41(5):596-9.

14. Michalakis KX, Hirayama H, Garefis PD. Cementretained versus screw-retained implant restorations: a critical review. Int J Oral Maxillofac Implants. 2003 Oct;18(5):719-28.

15. Sahu N, Lakshmi N, Azhagarasan NS, Agnihotri Y, Rajan M, Hariharan R. Comparison of the effect of implant abutment surface modifications on retention of implantsupported restoration with a polymer based cement. J Clin Diagn Res. 2014 Jan;8(1):239-42.

16. Michalakis K, Pissiotis AL, Kang K, Hirayama H, Garefis PD, Petridis $H$. The effect of thermal cycling and air abrasion on cement failure loads of 4 provisional luting agents used for the cementation of implant-supported fixed partial dentures. Int J Oral Maxillofac Implants. 2007 Aug;22(4):569-74.

17. Hitmi L, Attal JP, Degrange M. Influence of the timepoint of salivary contamination on dentin shear bond strength of 3 dentin adhesive systems. J Adhes Dent. 1999; $1(3): 219-32$.

18. Gale MS, Darvell BW. Thermal cycling procedures for laboratory testing of dental restorations. Journal of Dentistry. 1999 Feb;27(2):89-99. 
19. Kahng LS. Zirconium Abutments for Improved Esthetics in Anterior Restorations. The Journal of Cosmetic Dentistry. 2007; 22(4): 90-7.

20. Özarslan M, Güldag M. Retention of implant-supported zirconia copings over short zirconia and titanium abutments using four different luting agents. J Dent Implant. 2015;5(1):19.

21. Yu H, Zheng M, Chen R, Cheng H. Proper selection of contemporary dental cements. Oral Health Dent Manag. 2014 Mar;13(1):54-9.

22. Adhesion to Zirconia Used for Dental Restorations: A Systematic Review and Meta-Analysis. The Journal of Adhesive Dentistry. 2015 Jan 30;17(1):7-26.

23. Moura DMD, do Nascimento Januário AB, de Araújo AMM, de Oliveira Dal Piva AM, Özcan M, Bottino MA, et al. Effect of primer-cement systems with different functional phosphate monomers on the adhesion of zirconia to dentin. Journal of the Mechanical Behavior of Biomedical Materials. 2018 Dec;88:69-77.

24. TempBond Clear catalyst paste, material safety data sheet. Kerr Corporation. 2007.

25. Roman-Rodriguez J, Millan-Martinez D, Fons-Font A, Agustin-Panadero R, Fernandez-Estevan L. Traction test of temporary dental cements. J Clin Exp Dent. 2017; 9(4); e564-8.
26. Xie J, Powers J, Mcguckin R. In vitro bond strength of two adhesives to enamel and dentin under normal and contaminated conditions. Dental Materials. 1993 Sep;9(5):295-9.

27. el-Kalla IH, García-Godoy F. Saliva contamination and bond strength of single-bottle adhesives to enamel and dentin. Am J Dent. 1997 Apr;10(2):83-7.

28. Chung CWM, Yiu CKY, King NM, Hiraishi N, Tay FR. Effect of saliva contamination on bond strength of resin luting cements to dentin. Journal of Dentistry. 2009 Dec;37(12):923-31.

29. Anusavice KJ, Shen C, Rawls HR. Phillip's Science of Dental Materials: Kenneth J. Anusavice, PhD, DMD ; Chiayi Shen, $\mathrm{PhD}$; H. Ralph Rawls, PhD. Edition 12. St. Louis, Missouri: Elsevier; 2013: 243.

30. Vieyra JP. Effect of Five Lubricants on Root Canal Walls during the Impression Phase of an Endodontic Post. Dentistry [Internet]. 2015

31. Ribeiro da Silva CJ, Gonçalves ICS, Botelho MPJ, Guiraldo RD, Lopes MB, Gonini Júnior A. Interactions between resin-based temporary materials and immediate dentin sealing. Appl Adhes Sci. 2016 Dec;4(1):3.

32. Sakaguchi RL, Ferracane JL, Powers JM, editors. Craig's restorative dental materials. Fourteenth edition. St. Louis, Missouri: Elsevier; 2019: 289. 